\title{
TGF- $\beta 1$ expression is associated with invasion and metastasis of intrahepatic cholangiocarcinoma
}

\author{
Yijie Chen ${ }^{1}$, Lin Ma², Qian He ${ }^{1}$, Shaobo Zhang ${ }^{1}$, Chenghua Zhang ${ }^{1 *}$ and Wei Jia ${ }^{3 *}$
}

\begin{abstract}
Background: Transforming growth factor (TGF)- $\beta$ is involved in many physiologic processes, it often promotes metastasis, and its high expression is correlated with poor prognosis. In the present study, we analyzed the correlation between transforming growth factor beta 1 (TGF- $\beta 1$ ) expression and prognosis in intrahepatic cholangiocarcinoma.

Results: We examined the expression of TGF- $\beta 1$ in 78 intrahepatic cholangiocarcinomas by immunohistochemistry and correlated the expression with clinicopathological parameters. TGF- $\beta 1$ was expressed in 37 of 78 (47.4 \%) intrahepatic cholangiocarcinomas. The expression of TGF- $\beta 1$ was significantly correlated with lymph node metastasis, distant metastasis, and tumour recurrence. Patients with TGF- $\beta 1$-positive tumours had significantly shorter survival time. In a multivariant analysis, the expression of TGF- $\beta 1$ and the tumour stage were independent prognostic factors.
\end{abstract}

Conclusions: Our data suggest that expression of TGF- $\beta 1$ is a novel prognostic marker for intrahepatic cholangiocarcinoma.

Keywords: Intrahepatic cholangiocarcinoma, Transforming growth factor beta 1 (TGF- $\beta 1$ ), Prognosis

\section{Background}

Intrahepatic cholangiocarcinoma (ICC) is the second most common, primary hepatobiliary cancer after hepatocellular carcinoma. Despite overall advances in the diagnosis and treatment of patients with ICC, the prognosis of this disease still remains poor $[1,2]$. One of the most important factors influencing the dismal prognosis of ICC is based on the late diagnosis at an advanced stage of disease, when tumour cell invasion into the blood and lymphatic vessels has resulted in metastatic spread and complete curative resection can no longer be achieved [3]. However, the molecular mechanisms underlying and driving metastasis remain unclear.

Transforming growth factor (TGF)- $\beta$ is involved in various physiologic processes, such as wound healing, tissue development, and remodelling. TGF- $\beta$ has also been implicated in many pathological conditions, including cancer, and has been shown to regulate a number of critical processes, such as angiogenesis, immune suppression, and cell

\footnotetext{
*Correspondence: zchqzyy@126.com; scdxhxyy28@126.com

'General Surgery, The 180th Hospital of People's Liberation Army, Quanzhou, Fujian, China

${ }^{3}$ Department of Emergency Medicine, Tianjin Medical University General

Hospital, Tianjin, China

Full list of author information is available at the end of the article
}

migration [4-8]. TGF- $\beta$ also induces a cytostatic response in most normal cell types and promotes metastasis in malignant tumour cells. Furthermore, high expression of TGF- $\beta$ is correlated with poor prognosis in many malignant tumours [9-15].

There are three known mammalian isoforms of TGF$\beta$, TGF- $\beta 1,-\beta 2$, and $-\beta 3$, and all share significant structural and functional similarities [16]. Most malignant tumour cells exhibit positive TGF- $\beta 1$ expression, with the most prominent expression in the plasma $[14,17]$. Clinically, TGF- $\beta 1$ is often elevated in the plasma of patients with malignant tumours. Preclinically, several models have shown correlations between TGF- $\beta 1$ expression and increased tumourigenicity and increased invasion in many malignant tumours [8-10]. In this study, we analysed the expression of TGF- $\beta 1$ in 78 ICC cases by immunohistochemistry, and investigated the association between TGF- $\beta 1$ expression with clinicopathological parameters and patient survival.

\section{Results}

Expression of TGF- $\beta 1$ protein in ICC

In normal liver tissue, TGF- $\beta 1$ was not expressed in hepatocytes or bile ducts (Fig. 1a). TGF- $\beta 1$ was detected in 37 of 78 tumours $(47.4 \%)$. Among the 37 tumours 


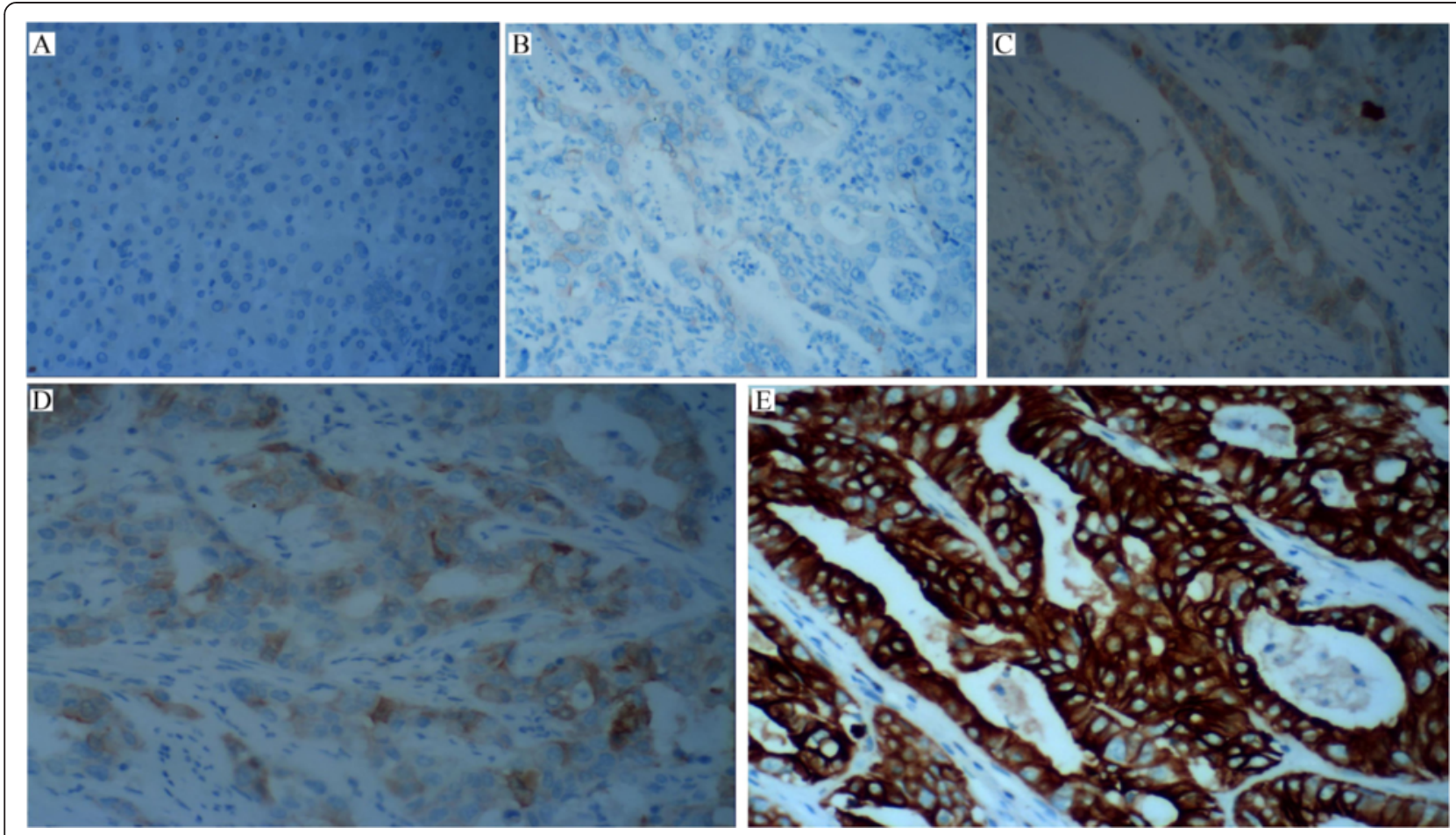

Fig. 1 Immunohistochemical staining of TGF- $\beta 1$ in ICC and normal liver. a TGF- $\beta 1$ is not expressed in hepatocyte or bile duct. b ICC with negative TGF- $\beta 1$ staining. $\mathbf{c}$ ICC with weak TGF- $\beta 1$ staining. d ICC with moderate TGF- $\beta 1$ cytoplasmic staining. e ICC with strong TGF- $\beta 1$ cytoplasmic staining ( $\times 200)$

positive for TGF- $\beta 1$ expression, 14 tumours had weak staining and 23 tumours had moderate to strong staining. The tumours showed cytoplasmic staining of TGF- $\beta 1$ (Fig. 1b-e). Generally, TGF- $\beta 1$ expression showed considerable heterogeneity in the intratumoral distribution.

\section{Clinicopathologic significance of TGF- $\beta 1$ expression in ICC} To evaluate whether TGF- $\beta 1$ protein was associated with clinicopathological features of patients with ICC, we correlated immunohistochemical TGF- $\beta 1$ staining results with major clinicopathologic features of ICC. As shown in Table 1 , TGF- $\beta 1$ expression was positively associated with lymph node metastasis, lymphovascular invasion, distant metastasis and tumour recurrence, but not with sex, patient age, tumour stage, and histologic differentiation or tumour size (pT).

\section{Univariant survival analysis}

In univariant survival analysis, we used the KaplanMeier method to calculate the cumulative survival curve and the differences in survival were accessed by the logrank method. The conventional prognostic parameters including tumour size, nodal status, and disease stage reached significance for the overall survival. Patients with TGF- $\beta 1$-positive tumours had a significant shorter survival than those with TGF- $\beta 1$-negative tumours $(P=0.017$; Fig. 2). The median survival of patients with
TGF- $\beta 1$-positive and-negative tumours was 7.3 and 16.6 months, respectively.

\section{Multivariant survival analysis}

A multivariant progression analysis based on the Cox proportional hazard model was performed to analyse the independent value of each parameter predicting overall survival (Table 2). In this analysis, we included tumour size, nodal status, disease stage, and TGF- $\beta 1$ expression. Tumour stage $(P=0.0000)$ and TGF- $\beta 1$ expression $(P=0.001)$ proved to be independent prognostic factors for shortened overall survival in ICC.

\section{Discussion}

In this study, we demonstrate that patients with ICC that express high levels of TGF- $\beta 1$ have a higher chance of tumour recurrence, lymph node metastasis, lymphovascular invasion and distant metastasis than those with tumours that lack TGF- $\beta 1$ expression. ICC is a highly aggressive tumour with generally poor prognosis characterized by intense desmoplastic stromal reaction and extensive vascular and perineural invasion.

In our series, immunohistochemical TGF- $\beta 1$ expression is an independent prognostic indicator for ICC patients irrespective of vascular and lymphovascular characteristics. The high significance of our statistical data supports the hypothesis that TGF- $\beta 1$ expression may interfere with the invasion process in ICC. TGF- $\beta 1$ is an upstream effector 
Table 1 TGF- $\beta 1$ expression and clinicopathologic parameters of ICC

\begin{tabular}{|c|c|c|c|}
\hline \multirow[b]{2}{*}{ Gender } & \multicolumn{2}{|c|}{ TGF- $\beta 1$ expression } & \multirow{2}{*}{$\frac{p \text {-value }}{0.654}$} \\
\hline & + & - & \\
\hline Male $(n=38)$ & 18 & 20 & \\
\hline Female $(n=40)$ & 19 & 21 & \\
\hline Age & & & 0.453 \\
\hline$<60$ years $(n=31)$ & 17 & 14 & \\
\hline$\geq 60$ years $(n=47)$ & 20 & 27 & \\
\hline Stage & & & 0.097 \\
\hline$|-| \mid(n=37)$ & 19 & 18 & \\
\hline III-IV (n= 41) & 18 & 23 & \\
\hline Size & & & 0.086 \\
\hline $\mathrm{T} 1-\mathrm{T} 2(\mathrm{n}=36)$ & 16 & 20 & \\
\hline T3-T4 $(n=42)$ & 21 & 21 & \\
\hline Lymph node metastasis & & & 0.003 \\
\hline Yes $(n=20)$ & 17 & 3 & \\
\hline No $(n=58)$ & 20 & 38 & \\
\hline Lymphovascular invasion & & & 0.045 \\
\hline Yes $(n=16)$ & 10 & 6 & \\
\hline No $(n=62)$ & 27 & 35 & \\
\hline Distant metastasis & & & 0.012 \\
\hline Yes $(n=8)$ & 8 & 0 & \\
\hline No $(n=70)$ & 29 & 41 & \\
\hline Histologic dedifferentiation & & & 0.145 \\
\hline Well differentiated $(n=42)$ & 21 & 21 & \\
\hline Moderately differentiated $(n=15)$ & 9 & 6 & \\
\hline Poorly differentiated $(n=21)$ & 7 & 14 & \\
\hline Tumour recurrence & & & 0.023 \\
\hline Yes $(n=47)$ & 26 & 21 & \\
\hline $\mathrm{No}(\mathrm{n}=31)$ & 11 & 20 & \\
\hline
\end{tabular}

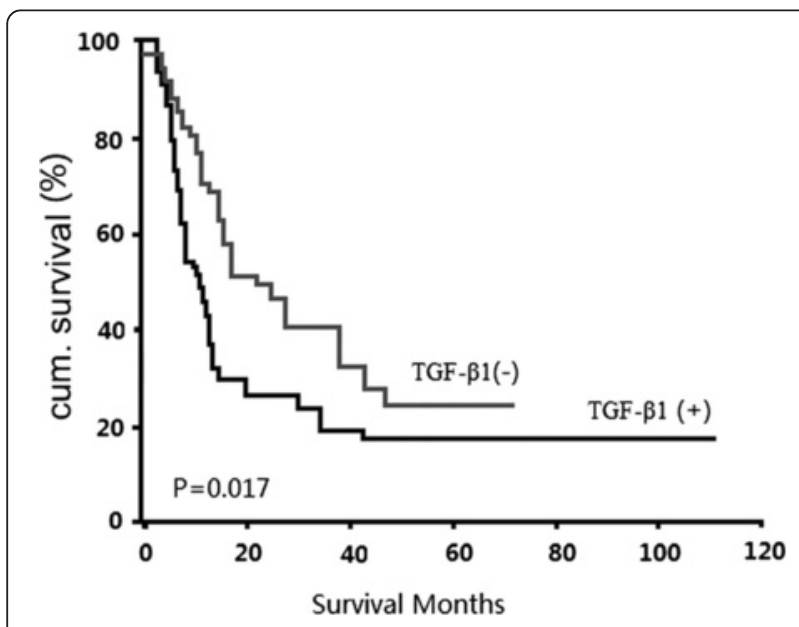

Fig. 2 Univariant survival analysis of TGF- $\beta 1$ in all 78 ICCS demonstrates that TGF- $\beta 1$ positive tumours are associated with poor prognosis
Table 2 Multivariant survival analysis (Cox regression model) shows TGF- $\beta 1$ and tumor stage are independent prognostic factor

\begin{tabular}{llllll}
\hline & Beta & Standard error & Wald & df & $p$-value \\
\hline Stage & 0.4973 & 0.1494 & 17.560 & 1 & 0.000 \\
TGF- $\beta 1$ & 0.6854 & 0.2981 & 5.853 & 1 & 0.001 \\
\hline
\end{tabular}

of MMPs and VEGF, which could promote invasion, angiogenesis, and proliferation in many cancers [1-6], and thus could be a biological predictor of survival for ICC patients [6]. However, the current understanding of invasion and metastasis processes in ICC is poor and future studies should focus on identification of the specific molecular pathways involving TGF- $\beta 1$ in these tumours.

The possibility of long-term survival of ICC patients depends on early diagnosis and the feasibility of a surgical resection in cases with localized disease [18, 19]. Patients not suitable for surgery generally face rapid disease progression with a survival rate of months according to the series [18]. Prognostic markers are needed to identify ICC patients with poor prognosis that might benefit from more aggressive surgical strategies [20].

Sulkowski et al. reported a high frequency of TGF- $\beta 1$ positive colorectal cancers (up to $87 \%$ of studied cases) with cytoplasmic accumulation both in malignant cells and inflammatory cells. Their results suggested that blockage of anticancer immunity is maintained by TGF$\beta 1$ and cell growth is not restricted by TGF- $\beta 1$ as much in cancer cells as in normal intestinal epithelial cells [21]. According to the clinical-pathological reports on ICC, we also found that vascular invasion was a poor prognostic predictor of early tumour recurrence in ICCs $(P<0.05)$ and tumour invasion was a poor prognostic factor only in pancreatic cancers at univariate analysis [22]. Expression of TGF- $\beta 1$ in our ICC series turned out to be a significant predictor of survival $(P=0.017)$ at univariate tests and an independent indicator of early tumour recurrence, regardless of vascular invasion.

\section{Conclusions}

Our results indicate that TGF- $\beta 1$ expression seems to represent a specific and independent neoplastic trait of ICC. Its immunohistochemical detection should provide a novel biological prognostic marker for ICC.

\section{Methods}

Ethical approval

The study was approved by The 180th Hospital of People's Liberation Army, Quanzhou, and written informed consents were obtained from all participants prior to study entry.

\section{Patients}

Between 2008 and 2012, 78 consecutive patients underwent surgical resection of ICC at General Surgery 
department at the 180th Hospital of the People's Liberation Army. The group comprised 38 men and 40 women with a mean age of 64 years (range, 23.678.3 years). The distribution of TNM staging was as follows: stage I, $n=32$; stage II, $n=8$; stage III, $n=21$, and stage IV, $n=16$. At the end of follow-up, 49 patients were dead. A total of 64 patients were followed up at least 12 months or until death.

\section{Immunohistochemical analysis}

Sections $(4 \mu \mathrm{m})$ mounted on poly-L-lysine-coated slides were incubated for $30 \mathrm{~min}$ at $60^{\circ} \mathrm{C}$, deparaffinised by standard methods, and placed in $0.05 \mathrm{M}$ Tris-HCI buffer, $\mathrm{pH}$ 7.2. Antigen retrieval was performed for $20 \mathrm{~min}$ in $10 \mathrm{~mm}$ sodium citrate buffer ( $\mathrm{pH} 6)$ heated at $95{ }^{\circ} \mathrm{C}$ in a steamer, followed by cooling for $20 \mathrm{~min}$. After blocking endogenous peroxidase activity with $0.3 \%$ aqueous hydrogen peroxide for $5 \mathrm{~min}$, the primary polyclonal rabbit anti-TGF- $\beta 1$ antibody (DAKO, Carpinteria, CA, USA) was incubated with the sections at a final dilution of $2 \mathrm{mg} / \mathrm{mL}$ for $30 \mathrm{~min}$. A control slide was incubated with Tris-HCI buffer substituted for the primary antibody. The DAKO LSAB ${ }^{\mathrm{Tu}}$ kit/HRP was used for the detection of immunostaining. The sections were counterstained with Mayer's haematoxylin. The staining intensity of TGF- $\beta 1$ was semiquantitatively scored as negative, weak or moderate/strongly positive. A complete negative staining was scored as negative. A weak staining was defined as a minimal but unequivocal staining in less than $10 \%$ of tumour cells. Stronger or more extensive staining was scored as moderate $(10-50 \%)$ or strong ( $\geq 50 \%)$ positive expression. For statistical analysis, patients with weak and moderate/strong staining were lumped together as the TGF- $\beta 1$-positive group in comparison with those with TGF- $\beta 1$-negative tumours.

\section{Statistical analysis}

Statistical analysis of TGF- $\beta 1$ expression between specimen groups was carried out using the unpaired $X^{2}$ test. Comparisons of clinicopathological factors (i.e. sex, age at diagnosis, histological type, pathological stage, differentiation, tumour stage, pathological stage, lymph node metastasis and metastasis) between positive-and negativestaining groups were performed using $X^{2}$ tests. The log-rank test was used to compare survival distributions between the positive and negative staining groups, and Kaplan-Meier curves were plotted for the two groups. The clinical factors were accounted as being reasonable by fitting Cox's proportional hazards models. Differences were considered statistically significant when the $P$-value was $<0.05$.

\section{Consent}

Written informed consent was obtained from the patient for the publication of this report and any accompanying images.

\section{Competing interests}

The authors declare that they have no competing interests.

\section{Authors' contributions}

YJC and QH collected the clinical material; $\mathrm{CHZ}$ and SBZ participated in the design of the study and performed the statistical analysis; WJ and $\mathrm{CHZ}$ carried out the immunohistochemical analysis; YJC and LM helped to draft the manuscript. All authors read and approved the final manuscript.

\section{Acknowledgement}

This work was supported by the Military youth support program of China (13QNP167).

\section{Author details}

${ }^{1}$ General Surgery, The 180th Hospital of People's Liberation Army, Quanzhou, Fujian, China. ${ }^{2}$ Department of General Surgery, the Eighth People's Hospital of Qingdao, Qingdao, Shandong, China. ${ }^{3}$ Department of Emergency Medicine, Tianjin Medical University General Hospital, Tianjin, China.

Received: 2 December 2014 Accepted: 15 May 2015

Published online: 21 May 2015

\section{References}

1. Neuhaus P, Jonas S, Bechstein WO, Lohmann R, Radke C, Kling N, et al. Extended resections for hilar cholangiocarcinoma. Ann Surg. 1999;230:808-18.

2. Farley DR, Weaver AL, Nagorney DM. "Natural history" of unresected cholangiocarcinoma: patient outcome after noncurative intervention. Mayo Clin Proc. 2005;70:425-9.

3. Bismuth $H$, Nakache $R$, Diamond T. Management strategies in resection for hilar cholangiocarcinoma. Ann Surg. 2002;215:31-8.

4. Donovan D, Harmey JH, Toomey D, Osborne DH, Redmond HP, BouchierHayes DJ. TGF- $\beta 1$ regulation of VEGF production by breast cancer cells. Ann Surg Oncol. 1997:4:621-7.

5. Huber MA, Kraut N, Beug H. Molecular requirements for epithelialmesenchymal transition during tumour progression. Curr Opin Cell Biol. 2005;17:548-58.

6. Jeon SH, Chae BC, Kim HA. Mechanisms underlying TGF- $\beta 1$-induced expression of VEGF and Flk-1in mouse macrophages and their implications for angiogenesis. J Leukoc Biol. 2007;81:557-66.

7. Pepper MS. Transforming growth factor- $\beta$ : vasculogenesis, angiogenesis, and vessel wall integrity. Cytokine Growth Factor Rev. 1997;8:21-43.

8. Muraoka RS, Dumont N, Ritter CA. Blockade of TGF- $\beta$ inhibits mammary tumour cell viability, migration, and metastases. J Clin Invest. 2002;109:1551-9.

9. Mitropoulos D, Kiroudi A, Christelli E, Serafetinidis E, Zervas A, Anastasiou I, et al. Expression of transforming growth factor beta in renal cell carcinoma and matched non-involved renal tissue. Urol Res. 2004;32:317-22.

10. Dong $L, G e X Y$, Wang $Y X$, Yang LQ, Li SL, Yu GY, et al. Transforming growth factor- $\beta$ and epithelial-mesenchymal transition are associated with pulmonary metastasis in adenoid cystic carcinoma. Oral Oncol. 2013;49:1051-8.

11. Reis ST, Pontes-Júnior J, Antunes AA, Sousa-Canavez JM, Abe DK, Cruz JA, et al. Tgf- $\beta 1$ expression as a biomarker of poor prognosis in prostate cancer. Clinics (Sao Paulo). 2011;66:1143-7.

12. Von Rahden $B H$, Stein HJ, Feith $M$, Pühringer $F$, Theisen J, Siewert JR, et al. Overexpression of TGF-beta1 in esophageal (Barrett's) adenocarcinoma is associated with advanced stage of disease and poor prognosis. Mol Carcinog. 2006:45:786-94.

13. Fukai Y, Fukuchi M, Masuda N, Osawa H, Kato H, Nakajima T, et al. Reduced expression of transforming growth factor-beta receptors is an unfavorable prognostic factor in human esophageal squamous cell carcinoma. Int J Cancer. 2003;104:161-6.

14. Saito H, Tsujitani S, Oka S, Kondo A, Ikeguchi M, Maeta M, et al. An elevated serum level of transforming growth factor-beta 1 (TGF-beta 1) significantly correlated with lymph node metastasis and poor prognosis in patients with gastric carcinoma. Anticancer Res. 2000;20:4489-93. 
15. Tsushima H, Kawata S, Tamura S, Ito N, Shirai Y, Kiso S, et al. High levels of transforming growth factor beta 1 in patients with colorectal cancer: association with disease progression. Gastroenterology. 1996;1 10:375-82.

16. Patil $A S$, Sable RB, Kothari RM. An update on transforming growth factor- $\beta$ (TGF- $\beta$ ): sources, types, functionsand clinical applicability for cartilage/bone healing. J Cell Physiol. 2011;226:3094-103.

17. Lin Y, Kikuchi S, Obata Y, Yagyu K. Tokyo Research Group on Prevention of Gastric Cancer. Serum levels of transforming growth factor beta1 are significantly correlated with venous invasion in patients with gastric cancer. J Gastroenterol Hepatol. 2006;21:432-7.

18. Krasagakis K, Thölke D, Farthmann B, Eberle J, Mansmann U, Orfanos CE. Elevated plasma levels of transforming growth factor (TGF)-beta1 and TGF-beta2 in patients with disseminated malignant melanoma. Br J Cancer. 1998;77:1492-4.

19. Nakagohri T, Asano T, Kinoshita H, Kenmochi T, Urashima T, Miura F. Aggressive surgical resection for hilar-invasive and peripheral intrahepatic cholangiocarcinoma. World J Surg. 2013;27:289-93.

20. Gores GJ. Cholangiocarcinoma: current concepts and insights. Hepatology. 2013;37:961-9.

21. Sulkowski S, Wincewicz A, Sulkowska M, Koda M. Ann N Y Acad Sci. 2009:1171:116-23.

22. Hanazaki K, Kajikawa S, Shimozawa N, Shimada K, Hiraguri M, Koide N. Prognostic factors of intrahepatic cholangiocarcinoma after hepatic resection: univariate and multivariate analysis. Hepatogastroenterology. 2012;49:311-6.

\section{Submit your next manuscript to BioMed Central and take full advantage of:}

- Convenient online submission

- Thorough peer review

- No space constraints or color figure charges

- Immediate publication on acceptance

- Inclusion in PubMed, CAS, Scopus and Google Scholar

- Research which is freely available for redistribution 